\title{
Breakthrough Pressure Prediction Based on Neural Network Model
}

\author{
Shuren Hao $\mathbb{D}^{1},{ }^{1}$ Jixiang Cao, ${ }^{1}$ Hua Zhang $\mathbb{D},{ }^{2}$ Yulian Liu $\mathbb{D}^{3}{ }^{\text {Haian Liang, }}{ }^{1}$ \\ and Mingdong $\mathrm{Li}^{1}$ \\ ${ }^{1}$ School of Civil \& Architecture Engineering, East China University of Technology, Nanchang 330013, China \\ ${ }^{2}$ Jiangxi Institute of Survey and Design, Nanchang 330095, China \\ ${ }^{3}$ School of Earth Science, East China University of Technology, Nanchang 330013, China
}

Correspondence should be addressed to Shuren Hao; 540668136@qq.com, Hua Zhang; 99445943@qq.com, and Yulian Liu; 1197086008@qq.com

Received 31 May 2021; Revised 27 July 2021; Accepted 27 September 2021; Published 9 November 2021

Academic Editor: Zhongqiong Zhang

Copyright (c) 2021 Shuren Hao et al. This is an open access article distributed under the Creative Commons Attribution License, which permits unrestricted use, distribution, and reproduction in any medium, provided the original work is properly cited.

\begin{abstract}
The increasing carbon dioxide content is identified as the main cause of global warming. Capturing carbon dioxide in the atmosphere and transporting it to deep salt layer for storage have been proven and practiced in many aspects, which considered to be an effective way to reduce the content of carbon dioxide in the atmosphere. The sealing property of cap rocks is one of the key factors to determine whether $\mathrm{CO}_{2}$ can be effectively stored for a long time. In view of the disadvantages of tedious and time-consuming laboratory test methods for breakthrough pressure of cap rock, this paper explores the relationship between breakthrough pressure and other parameters such as porosity, permeability, density, specific surface area, maximum throat radius, and total organic carbon. The results show that the rock breakthrough pressure is closely related to the maximum throat radius and permeability determined by the mercury injection method, followed by the porosity and specific surface area, and less related to the density, depth, and TOC content of the rock itself. Then, with the selected parameters, a neural network model is established to predict the breakthrough pressure of cap rock, which can achieve good prediction results.
\end{abstract}

\section{Introduction}

For more than a decade, the problem of greenhouse gas effects has been one of the focuses of research. Scholars have conducted numerous studies on the continuous increase of $\mathrm{CO}_{2}$ content in the atmosphere and the problem of greenhouse effect $[1,2]$. One of the main causes of the greenhouse effect was the continuous increase of $\mathrm{CO}_{2}$ concentration in the atmosphere $[3,4]$. The storage of $\mathrm{CO}_{2}$ in deep saline aquifers has attracted much attention due to its large capacity, long-term storage, and even permanent closure $[5,6]$.

The sealing ability of cap rocks is essential to the success of $\mathrm{CO}_{2}$ storage [7]. When stored in saturated brine formation, high negative capillary pressure is formed in the pores of the rock due to the nonwetting properties of the injected $\mathrm{CO}_{2}$. The capillary pressure of reservoir rock and cap rock differs due to the difference in their pore throat radius. Capillary pressure must be addressed in the process of $\mathrm{CO}_{2}$ seepage. Therefore, breakthrough pressure must be satisfied for $\mathrm{CO}_{2}$ gas to pass through mudstone caprock [7].

Various methods could be used for testing the breakthrough pressure of cap rock, including indirect and direct methods. Amongst them, the mercury intrusion method is an indirect method, whilst the displacement method, the step method, the continuous method, and the pulse method are direct methods [8]. In 1968, Thomas et al. [9] used nitrogen to carry out breakthrough pressure tests by gradually increasing the injection pressure on the rock sample. Ibrahim et al. in 1970 and Schowalter in 1979 [10, 11] separately used a step-by-step method (where the pressure is gradually applied to one side of the rock until the gas breaks through the rock) to test the breakthrough pressure of rocks. 
In 1985, Busch et al. tested the consolidated MX-80 bentonite and pointed out that the breakthrough pressure is related to the expansion pressure.

As critical capillary pressures of mudrocks are extraordinarily difficult to measure in the laboratory and experiments often turned out to be extremely time consuming, the present study is aimed at finding "simple" rules [12]. The conventional method is to determine the relationship between breakthrough pressure and other standard parameters, which is easy to measure.

The factors that affect the breakthrough pressure of rocks are complex. Numerous studies have shown that contact angle and surface tension are closely related to clay minerals, temperature, pressure, burial depth, and other parameters [12-14]. Some scholars have attempted to predict the breakthrough pressure of mudstone by using the parameters of porosity and permeability, but the testing accuracy and applicable range could not meet the needs for evaluation.

As the core technology of artificial intelligence, the artificial neural network (ANN) has been widely used in daily life, invention, and creation; it also plays a role in promoting academic research in various fields. In the field of chemistry, scholars use the concept of the ANN model to study different methods to predict the solubility of hydrogen sulphide in various ionic liquids. For instance, the content of dissolved calcium carbonate in oilfield brine was determined. ANN was also used to build a model for $\mathrm{CO}_{2}$ foam flooding to improve indoor oil recovery [15], accurately predict asphaltene precipitation caused by natural exhaustion [15], and monitor network permeability and porosity [16]. The combination of swarm intelligence and ANN was used to predict the chemical displacement efficiency of reservoirs [17] and further understand the fluid behaviour of reservoirs through a reservoir simulation scenario. In the present paper, various rock parameters were combined to establish a neural network model to predict the $\mathrm{CO}_{2}$ breakthrough pressure of rocks and further improve the accuracy and universal trial range of the prediction results.

The entire dataset contains data from nuclear waste storage, hydrocarbon sealing, and $\mathrm{CO}_{2}$ storage research, including rock permeability, porosity, maximum throat radius, specific surface area, and total organic carbon (TOC). In this paper, a neural network model was used to comprehensively analyse the relationship between these factors and the breakthrough pressure of rocks, and a prediction model of breakthrough pressure of mudstone was established.

\section{Data Acquisition and Processing}

As the breakthrough pressure test takes a long time and the number of tests is limited, the test data in this article could not meet the needs for statistical analysis. Therefore, several sets of test data related to breakthrough pressure were collected by consulting the literature, including 158 sets of mudstone shale and 14 sets of sandstone test data, which consisted of breakthrough (capillary) pressure, porosity, permeability, maximum throat radius, specific surface area, and other parameters. Table 1 shows the data sources collected, number of samples, data types, and quantity. Although the parameters measured in each literature were not exactly the same, a considerable number of statistical results were obtained for regularity analysis.

This article focused on the study of the breakthrough pressure of $\mathrm{CO}_{2}$ in saturated mudstone. The data collected in this article included not only the breakthrough pressure of $\mathrm{CO}_{2}$ but also the breakthrough pressure test data of $\mathrm{N}_{2}$, $\mathrm{CH}_{4}, \mathrm{He}$, and other gases and the breakthrough medium pressure test data of $\mathrm{Hg}$. However, the relationship between the surface tension and the wetting angle of the two-phase media could be converted using the following formulas [31]:

$$
P_{c \cdot \text { brkth } \cdot \mathrm{CO}_{2}}=P_{c \cdot x} \cdot \frac{\gamma_{\mathrm{CO}_{2} \text {-brine }}}{\gamma_{x \text {-brine }}},
$$

where $x$ means non- $\mathrm{CO}_{2}$ gas $\left(\mathrm{N}_{2}, \mathrm{CH}_{4}\right.$, and $\left.\mathrm{He}\right)$.

Parameters such as contact angle and interfacial tension are required to recalculate the breakthrough pressure of other gases on the basis of $\mathrm{Hg}$ pressure measurement data. The conversion formula could be expressed as follows:

$$
P_{c \cdot \text { brkth } \cdot x}=P_{c \cdot \text { entry } \cdot \mathrm{Hg}} \cdot \frac{\gamma_{x \text {-brine }} \cdot \cos \left(\theta_{x}\right)}{480(\mathrm{mN} / \mathrm{m}) \cdot \cos \left(141^{\circ}\right)} .
$$

The surface tension of gas is affected by temperature and pressure. Heath et al. [32] summarised the previous research results and pointed out the relationship between surface tension and temperature pressure, as shown in Figure 1.

For the values of the surface tension in different gases, the fitting curve proposed by Busch et al. [33] was used in the present paper on the basis of previous research results. The surface tension of $\mathrm{CH}_{4}, \mathrm{~N}_{2}, \mathrm{CO}_{2}$, and $\mathrm{H}_{2}$ with temperature and pressure could be expressed as follows:

$$
\begin{aligned}
& \gamma_{\mathrm{CH}_{4}}=67.26-0.926 \cdot p+0.011 \cdot p^{2}-0.119 \cdot\left(T-T_{\mathrm{ref}}\right), \\
& \gamma_{\mathrm{N}_{2}}=66.03-0.353 \cdot p+0.011 \cdot p^{2}-0.169 \cdot\left(T-T_{\mathrm{ref}}\right), \\
& \gamma_{\mathrm{CH}_{4}}=49.08-1.582 \cdot p+0.032 \cdot p^{2}-0.100 \cdot\left(T-T_{\mathrm{ref}}\right), \\
& \gamma_{\mathrm{CH}_{4}}=72.00-0.028 \cdot p-0.165 \cdot\left(T-T_{\mathrm{ref}}\right) .
\end{aligned}
$$

where $p$ is the pressure $(\mathrm{MPa}), T$ is the temperature $(\mathrm{K})$, and $T_{\text {ref }}$ is the reference temperature $\left(333 \mathrm{~K}\right.$ for $\mathrm{CH}_{4}$ and $\mathrm{N}_{2}$, $298 \mathrm{~K}$ for $\mathrm{He}$, and $348 \mathrm{~K}$ for $\mathrm{CO}_{2}$ ).

In accordance with the relationship of the above formulas, the breakthrough pressure test data of different breakthrough gases for different sources were converted into the breakthrough pressure value of $\mathrm{CO}_{2}$ breakthrough brine to conduct a unified analysis. The effect of a single factor on the breakthrough pressure was analysed separately. The pressure was determined by the pore throat radius, the wetting angle, and the surface tension. According to previous studies, porosity, permeability, specific surface area, and density could reflect the size and arrangement of rock porosity which are closely related to the pore throat radius. The depth of rocks is closely related to the pore pressure in deeply buried underground environments. According to 
TABLE 1: Mudstone breakthrough pressure test data obtained through literature review.

\begin{tabular}{|c|c|c|c|c|c|c|c|c|}
\hline \multirow[b]{2}{*}{ References } & \multicolumn{8}{|c|}{ Data type and quantity obtained } \\
\hline & Depth & Porosity & Permeability & $\begin{array}{c}\text { Specific } \\
\text { surface area }\end{array}$ & TOC & Density & $\begin{array}{l}\text { Maximum } \\
\text { throat radius }\end{array}$ & $\begin{array}{l}\text { Breakthrough } \\
\text { pressure }\end{array}$ \\
\hline Daisuke Ito et al. (2011) [18] & 3 & 3 & 3 & - & - & - & - & 3 \\
\hline Hildenbrand et al. $(2002,2004)[19,20]$ & 39 & 39 & 32 & 33 & 38 & - & 39 & 34 \\
\hline Yang and Aplin $(1998,2007)[14,21]$ & 30 & 30 & 30 & 30 & 30 & - & 20 & - \\
\hline Al-Bazali et al. $(2005,2009 b)[22,23]$ & - & - & 3 & - & - & - & - & 3 \\
\hline Marschall et al. (2005) [24] & - & 6 & 6 & 6 & - & 6 & - & 6 \\
\hline Amann-Hildenbrand et al. (2013) [25] & - & 15 & 9 & 13 & 14 & 15 & 15 & 15 \\
\hline Boulin et al. (2011) [26] & - & 2 & 2 & - & - & & - & 2 \\
\hline Zhang and $\mathrm{Yu}(2016)$ [27] & 4 & 4 & - & 4 & 4 & 4 & - & 4 \\
\hline Espinoza and Santamarina (2017) [28] & - & - & 5 & 5 & - & 5 & - & 5 \\
\hline Ono et al. (2013) [29] & - & 15 & 15 & - & - & 15 & - & 15 \\
\hline Gao Shuai et al. (2015) [8] & - & - & - & - & - & - & - & 4 \\
\hline $\begin{array}{l}\text { Huang Haiping and Deng Hongwen } \\
\text { (1995) [13] }\end{array}$ & 17 & 11 & 11 & 15 & 16 & 16 & 16 & 16 \\
\hline Schlömer and Krooss (1997) [30] & 27 & 26 & 27 & 27 & 27 & - & - & 27 \\
\hline
\end{tabular}

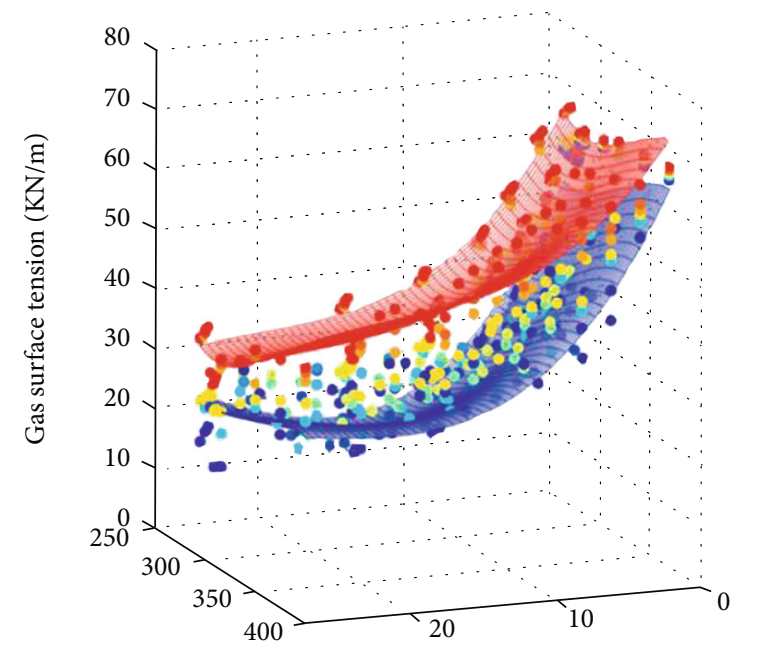

Temperature (K)

Stress (MPa)

Ionic strength $(\mathrm{M})$

$\begin{array}{ll}-6.6 \mathrm{e}+000 & -1.4 \mathrm{e}+000 \\ -5.7 \mathrm{e}+000 & -8.5 \mathrm{e}-001 \\ -4.5 \mathrm{e}+000 & -3.5 \mathrm{e}-001 \\ -2.9 \mathrm{e}+000 & -8.5 \mathrm{e}-002 \\ -2.6 \mathrm{e}+000 & -2.0 \mathrm{e}-017 \\ -1.7 \mathrm{e}+000 & -0.0 \mathrm{e}+000\end{array}$

Figure 1: Relationship between gas surface tension and temperature, pressure, and ionic strength [32].

the above analysis, the depth of rocks could affect the surface tension of gas and then the breakthrough pressure. The clay mineral content in the mineral composition could also affect the wetting angle and surface tension. The influence of each factor on the breakthrough pressure of rocks was analysed, the quantitative relationship between each factor and the breakthrough pressure was explored, the main factors that affect the breakthrough pressure were determined through analysis, and a predictive model was established by neural network calculation method.

\section{Correlation Analysis of Factors Affecting Breakthrough Pressure}

3.1. Relationship between Breakthrough Pressure and Permeability. In this section, the relationship between the permeability of rocks and $\mathrm{CO}_{2}$ was mainly explored. The data were not uniform because the collected data mostly came from literature collection. The collected permeability data mainly includes water, brine, and gas permeability. The main study involved the storage of $\mathrm{CO}_{2}$ in the brine layer. Therefore, the relationship between saltwater permeability and the breakthrough pressure of $\mathrm{CO}_{2}$ was mainly explored in this section. Firstly, the relationship between brine permeability and gas permeability was analysed, and then the relationship between brine permeability and pure water permeability was analysed to unify the data. Hildenbrand et al. [19] conducted permeability tests on homogenous rocks (mudstone and sand mudstone) by using pure water and saltwater and used the collected data to establish the relationship between the saltwater permeability of rocks and water permeability, as shown in Figure 2. Saltwater permeability and water permeability show a good correlation, and the ratio between them is approximately 1 . Therefore, in the data obtained in this article, this was analysed as saltwater permeability for some water-only permeability data sets.

Permeability is a parameter that characterises the rock's ability to conduct liquid. It closely relates to rock porosity and rock pore geometry. The pressure of $\mathrm{CO}_{2}$ passing through a rock is determined by the geometry of the rock pore and the size of the rock pore. Therefore, some relationships must exist between the permeability of rocks and the breakthrough pressure of $\mathrm{CO}_{2}$.

On the basis of many data obtained in this paper, a relationship diagram between saltwater permeability and the 


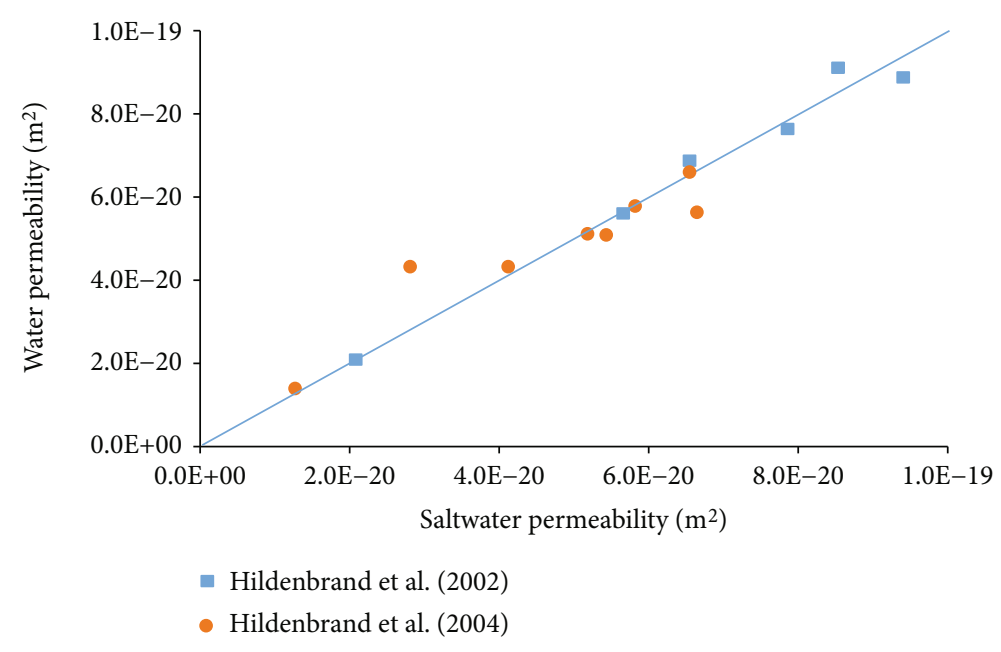

FIGURE 2: Relationship between saltwater permeability and water permeability.

breakthrough pressure value of $\mathrm{CO}_{2}$ was established, as shown in Figure 3. Some of the rock breakthrough pressure data were obtained from $\mathrm{CH}_{4}, \mathrm{H}_{2}$, or $\mathrm{N}_{2}$. The breakthrough pressure values of other gases were analysed in accordance with the conversion of Formulas (2) and (3) into $\mathrm{CO}_{2}$ breakthrough pressure values of saturated brine rock samples to facilitate a uniform analysis of the data. The value of the surface tension of different gases was calculated using Formulas (4), (5), (6), and (7).

Figure 3 shows that the saltwater permeability of rocks and the breakthrough pressure of $\mathrm{CO}_{2}$ in saturated brine rocks show a strong correlation on the whole. With the increase in permeability, the breakthrough pressure of the rock shows a fast downward trend. The fitting relationship between the saltwater permeability $k$ rate of the rock and the breakthrough pressure $P_{C \text {-brkth }}$ of $\mathrm{CO}_{2}$ is as follows:

$$
\begin{gathered}
\operatorname{Lg}\left(P_{C \text {-brkth }}\right)=-0.279 \lg k-5.097 \\
\left(n=139, R^{2}=0.49\right) .
\end{gathered}
$$

In view of the wide range of sources of data collected, despite the differences in sampling locations, origin, development history, and even rock testing methods for rock samples and the overall correlation coefficient $\left(R^{2}\right)$ being $0.49<0.5$, the relationship between pressure and permeability still shows a good correlation. A strong internal relationship is also found between rock permeability and breakthrough pressure. In the test data from the same source, the relationship between the breakthrough pressure value of $\mathrm{CO}_{2}$ and saltwater permeability is more obvious. For general rocks with a wide range of sources, a large error exists in predicting their breakthrough pressure value when using their permeability. Therefore, to predict the breakthrough pressure more accurately, the analysis needs to be performed in conjunction with other rock parameters. Comparison between Figures 3 and 4 shows a certain difference between the breakthrough pressure determined by the $\mathrm{Hg}$ intrusion method and the gas breakthrough pressure. Thus, the breakthrough pressure determined by the $\mathrm{Hg}$ method could not fully reflect the rock's ability to seal gas.
3.2. Relationship between Breakthrough Pressure and Porosity. Porosity, as an important indicator of the development of rock pores, is closely related to rock permeability [34]. In Section 3.1, rock permeability and breakthrough pressure were explored, and the results showed a close relationship between the two. The relationship between rock porosity and the breakthrough pressure of $\mathrm{CO}_{2}$ is shown in Figure 5. The higher the rock porosity is, the greater its breakthrough pressure. In general, rock porosity is positively correlated with rock permeability [35]. The higher the rock porosity is, the larger the pore throat radius. Thus, the rock's breakthrough pressure is higher, which is consistent with the general law. Although the overall trend is consistent, it is obtained through the fitted exponential relationship curve. In addition, $R^{2}<0.1$, showing almost no correlation. However, for the data from the same source, the correlation between porosity and breakthrough pressure is strong, whereas the composition of the data from Hildenbrand et al. in 2002 and 2004 [19, 20] and Schlömer and Krooss in 1997 [30] is weakly correlated. The data from Sprunt in 2006 [36] is moderately correlated. The remaining data groups show strong correlations.

In the data of porosity less than $30 \%$, the breakthrough pressure value of rocks decreases with the increase in porosity. For the data from Ono et al. [29], the porosity is between 35\% and $45 \%$ and the breakthrough pressure of rocks shows an increasing trend with the increase in porosity. The reason is the connectivity of rock's own pores and its pore structure and composition. However, as only the set of data in this paper demonstrates the phenomenon that the breakthrough pressure increases with the increase in porosity and this set has less data, it could not be considered as a general rule. The analysis of its internal factors was not discussed in detail in this paper. However, this phenomenon explains that the level of rock porosity could reflect the breakthrough pressure of rocks to a limited extent. The connectivity of rock's pores and its pore structure and morphology could all have a great effect on breakthrough pressure.

3.3. Relationship between Breakthrough Pressure and Maximum Roaring Radius. Breakthrough pressure refers to 


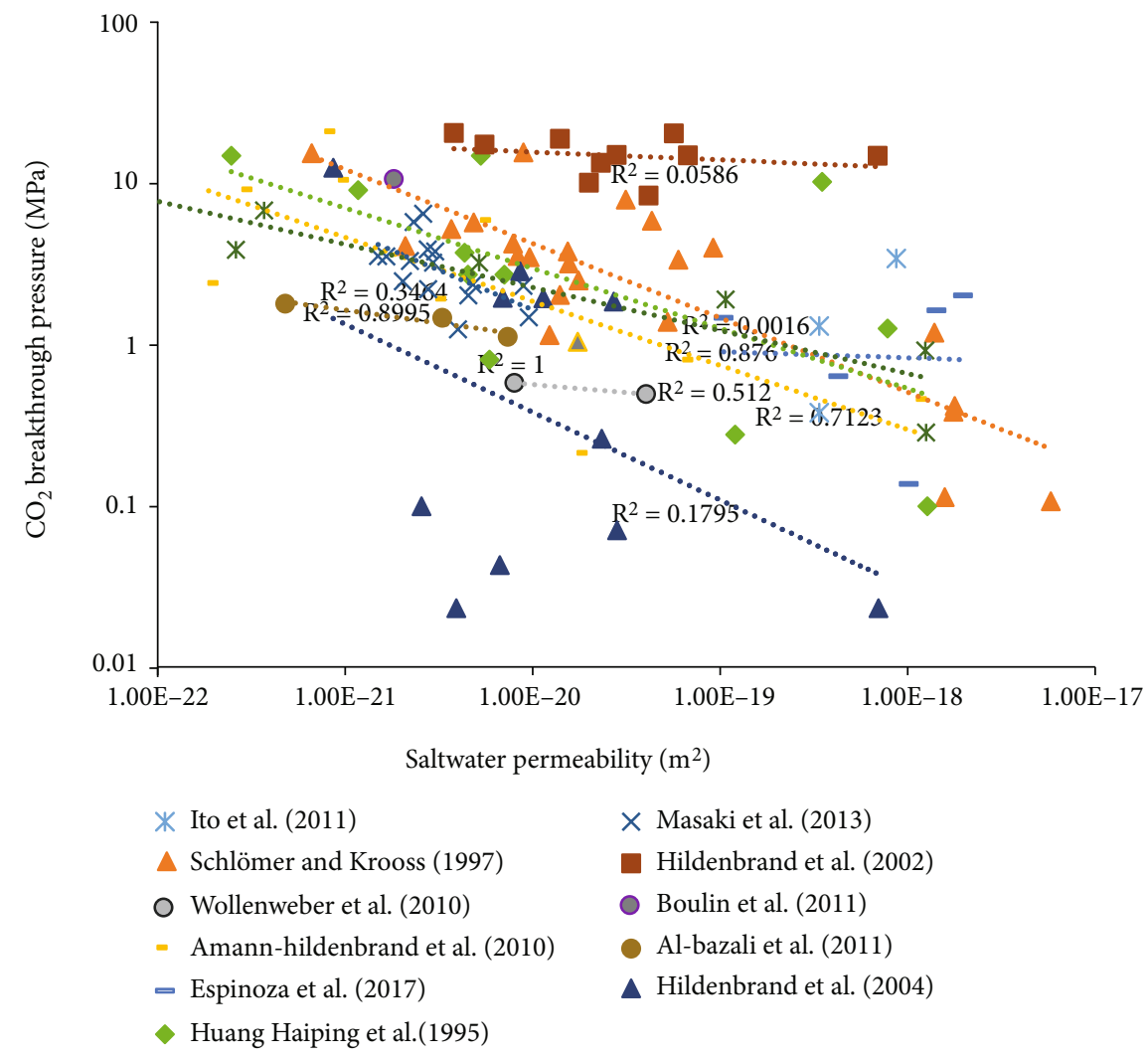

FigURE 3: Relationship between saltwater permeability and breakthrough pressure of $\mathrm{CO}_{2}$.

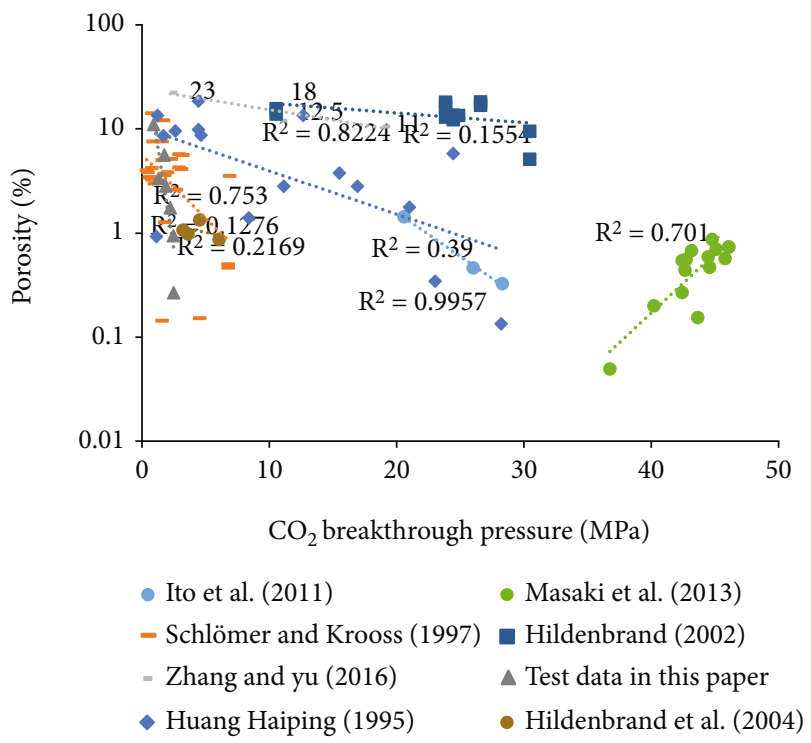

FIGURE 4: Relationship between porosity and $\mathrm{CO}_{2}$ breakthrough pressure.

the minimum pressure of the nonwetting phase fluid to displace the wetting phase fluid, and displacement pressure refers to the minimum capillary pressure corresponding to the largest connected pore size in rock. Thus, the breakthrough pressure of rocks is closely related to its maximum pore size. The relationship between the breakthrough pressure of rock $\mathrm{CO}_{2}$ and the maximum pore size of rocks was estab- lished, as shown in Figure 5. The breakthrough pressure has a strong correlation with the maximum aperture. With the increase in maximum pore diameter, the breakthrough pressure of rocks decreases sharply. The overall $R^{2}$ is 0.569 , showing a strong correlation. For data from the same source, the $R^{2}$ is approximately 0.7 , also showing a strong correlation. However, due to different pore morphologies, rock compositions, temperatures, pressure conditions, and other factors, the surface tension and contact angle between gas-phase and liquidphase fluids are affected to varying degrees, thereby causing some errors in the estimation of rock breakthrough pressure.

3.4. Relationship between Breakthrough Pressure and Specific Surface Area. The specific surface area of rocks refers to the total internal surface area of pores in unit volume or the total surface area of rock skeletons in unit volume of rocks. Given that the surface of rock pores is the boundary of fluid flow, its size could determine many properties of rocks and especially has a greater effect on the fluid flow in the reservoir. The specific surface area of rocks is related to their structure and morphology. Thus, a certain relationship possibly exists between the specific surface area and the breakthrough pressure. The relationship between the specific surface area of rocks and the breakthrough pressure of rock $\mathrm{CO}_{2}$ was established by summarising data, as shown in Figure 6. As the specific surface area increases, the breakthrough pressure shows an increasing trend because the larger the specific surface area of the rock is, the finer the particles, thus reducing the pore radius and increasing the breakthrough pressure. 


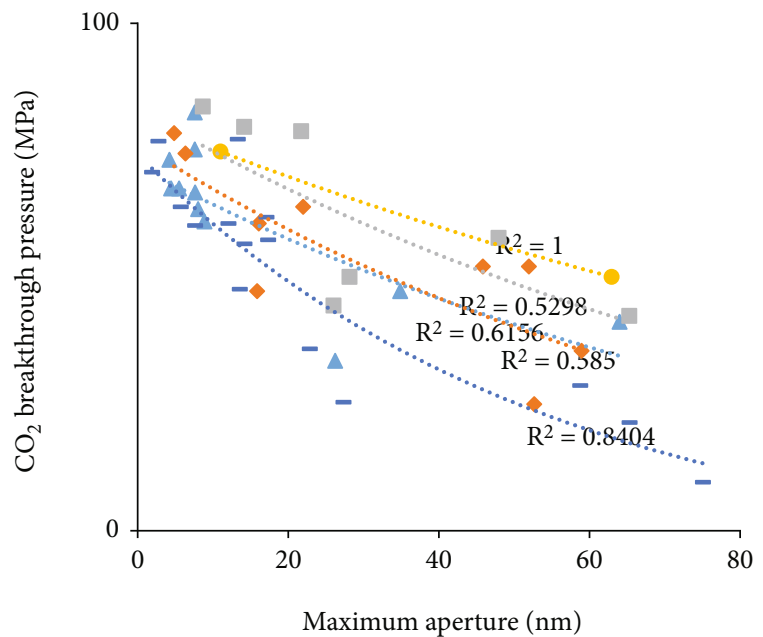

Amann-hildenbrand et al. (2013)
Huang Haiping et al. (1995)
Hildbrand et al. (2002)
- Boulin et al. (2011)
- Hildbrand et al. (2004)

FIGURE 5: Relationship between maximum aperture and breakthrough pressure of $\mathrm{CO}_{2}$.

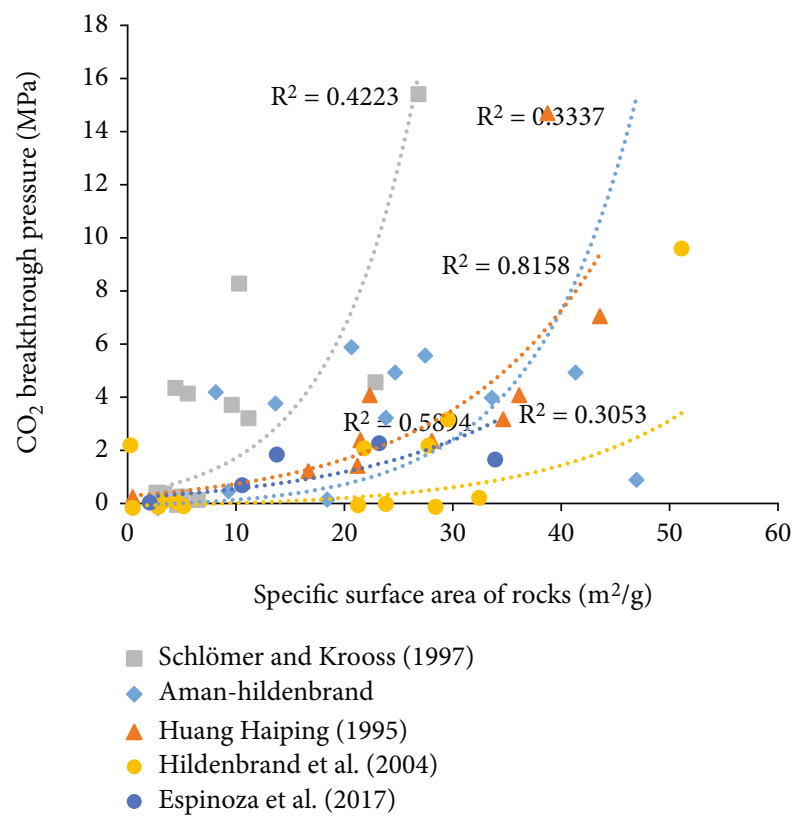

FIGURE 6: Relationship between specific surface area of rocks and $\mathrm{CO}_{2}$ breakthrough pressure.

The higher the degree of cementation is between the rock particles, the smaller the specific surface area of the rock and the better the cementation. The degree could reduce the permeability of the rock's pores, also leading to an increase in breakthrough pressure. From these two aspects, the specific surface area of the rock could break through it. The effect of the force is multiple. The characteristics of the rock pores are related to the genesis and development history of the rock, which led to a large difference in the breakthrough pressure between rocks of

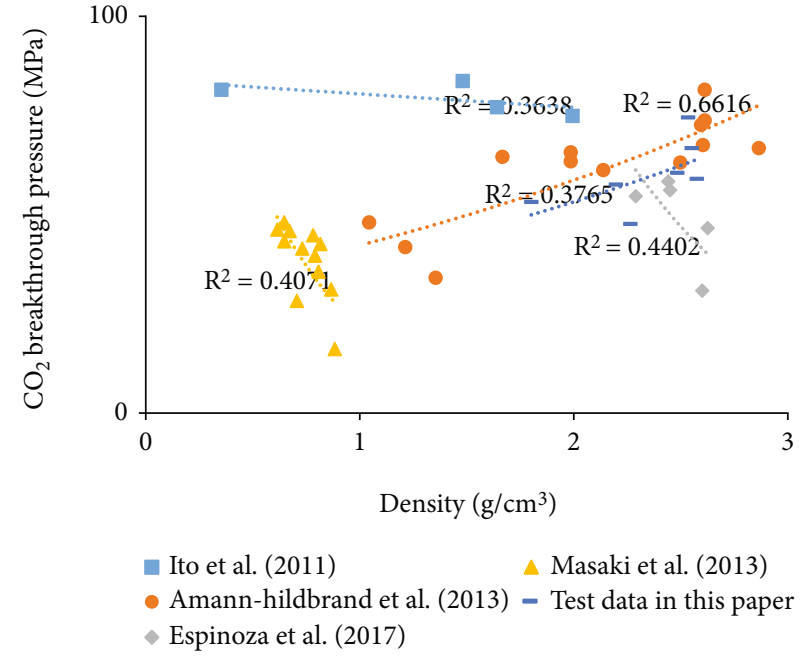

FIgURE 7: Relationship between density and breakthrough pressure of $\mathrm{CO}_{2}$.

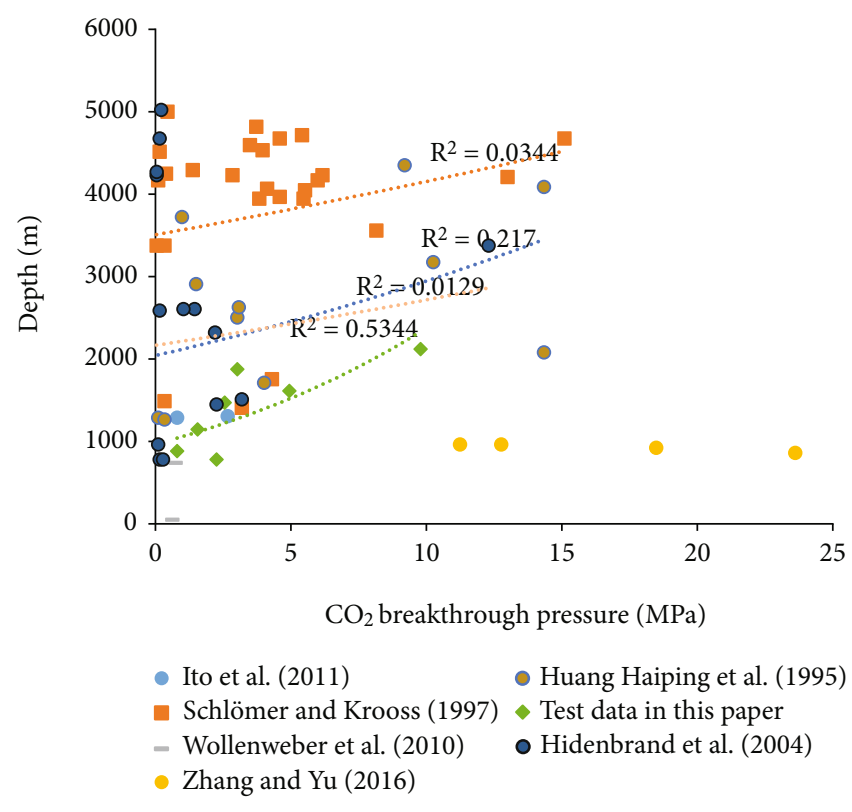

FIGURE 8: Relationship between $\mathrm{CO}_{2}$ breakthrough pressure and depth.

different sources with similar specific surface area. A large difference exists in the degree of correlation. For rocks of the same source, a certain relationship exists between the specific surface area and the breakthrough pressure. According to the fitted exponential curve, most of the $R^{2}$ values are between 0.3 and 0.5 , showing moderately relevant characteristics. Therefore, combining the specific surface area of rocks to predict their breakthrough pressure could further improve the prediction accuracy.

3.5. Relationship between Breakthrough Pressure and Density and Depth. The natural density of a rock could reflect its compactness to a certain extent. In general, the higher the density of a rock, the better its cementation and the higher its breakthrough pressure. Figure 7 shows that the 


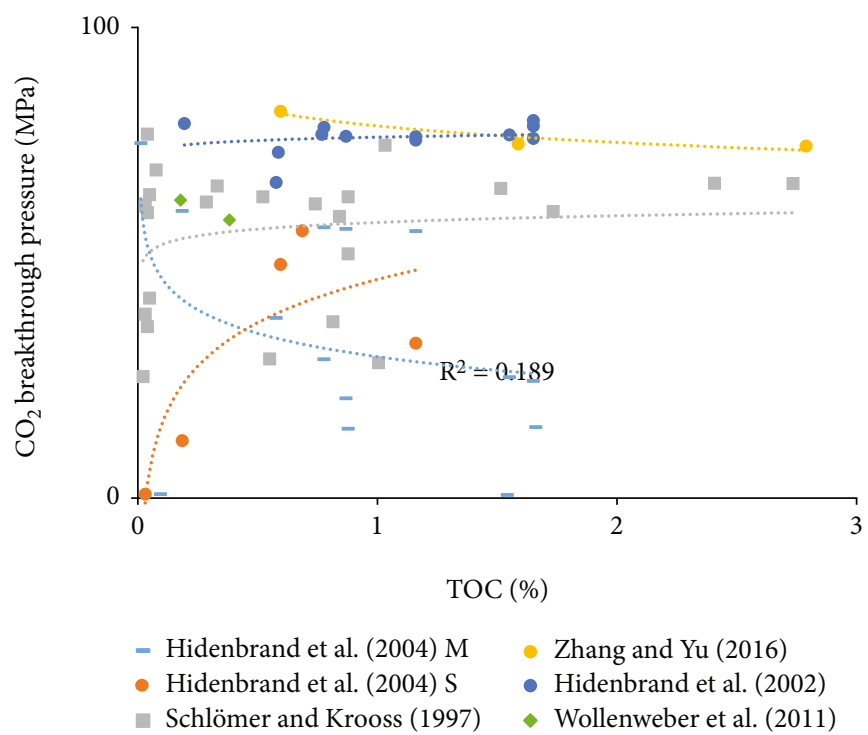

FIgURE 9: Relationship between TOC and breakthrough pressure of $\mathrm{CO}_{2}$.

breakthrough pressure of rocks generally increases with the increase in their density. According to the fitting relationship, the $R^{2}$ of 0.126 is weakly correlated. However, the natural density of rocks is considerably affected by their mineral composition and content. Therefore, the relationship between the density of rocks formed under different conditions and the breakthrough pressure of $\mathrm{CO}_{2}$ also shows different trends. Amongst them are rocks that appeared from the data sets of Espinoza and Santamarina in 2017 [28] and Masaki et al. [29]. The decrease in breakthrough pressure with increasing density also shows that the relationship between rock density and breakthrough pressure is not strong.

Figure 8 shows the breakthrough pressure and depth of rocks. For rocks of the same source, the breakthrough pressure tends to increase with increasing depth. The reason is that for the same type of rocks, the deeper the depth is, the denser the rock, and the better the degree of cementation, leading to a decrease in rock permeability and an increase in breakthrough pressure. However, according to the overall data, no correlation exists between the breakthrough pressure of a rock and its depth. As the development of crust differs amongst various sites, the sedimentary conditions and development environment of a rock has a great influence on the development of its composition, morphology, and pores [35]. During rock development, geological activities could cause strong disturbances to the depth of rocks. Thus, finding the regularity of the breakthrough pressure of mudstones in different regions is difficult.

3.6. Relationship between Breakthrough Pressure and TOC. Jarvie et al. in 2007 [37] and Wang and Gale in 2009 [38] pointed out that the brittleness of rocks in TOC distribution is often high, which makes microfractures easy to develop. In Cheng's [39] 2018 study on the breakthrough pressure of carboniferous shale in Qaidam Basin, the breakthrough pressure of rocks and TOC showed a good correlation. Combined with the results of scanning electron microscopy, the brittleness was affected by TOC, which generated more microfissures in the place where it was distributed and then formed microfissure channels, resulting in the breakthrough pressure of the rock showing a decreasing trend with the increase in TOC content. From the data of different site sources, the above rules are not general. Figure 9 illustrates that the breakthrough pressure of $\mathrm{CO}_{2}$ and the TOC content of rocks does not fully follow the above rules. The reason is that the development of microfractures in rocks could be affected by TOC content; however, this is not the main factor. The development of microcracks in rocks is determined by the stress state experienced during the development process. The stress history of rocks at different sites is considerably different, resulting in the different fitting curves of rock data from different sources in the graph. Therefore, according to the data collected in this article, the TOC content could not fundamentally reflect the magnitude relationship of the breakthrough pressure of rocks.

\section{Prediction of Breakthrough Pressure of Mudstone Based on Neural Network Algorithm}

On the basis of extensive data collection, several factors that may have a significant effect on the breakthrough pressure of rocks were analysed. The regularity and correlation of rock permeability, porosity, maximum throat radius, specific surface area, density, depth, and the breakthrough pressure of TOC and $\mathrm{CO}_{2}$ were also analysed. The results showed that the breakthrough pressure of a rock is most closely related to its permeability and maximum throat radius, followed by the relationship between porosity and specific surface area. In other words, the relationship between the density and sampling depth of rocks and TOC content is the weakest, and almost no correlation could be found. However, the influence of rock permeability and throat radius on breakthrough pressure is limited by its site. Thus, predicting and 


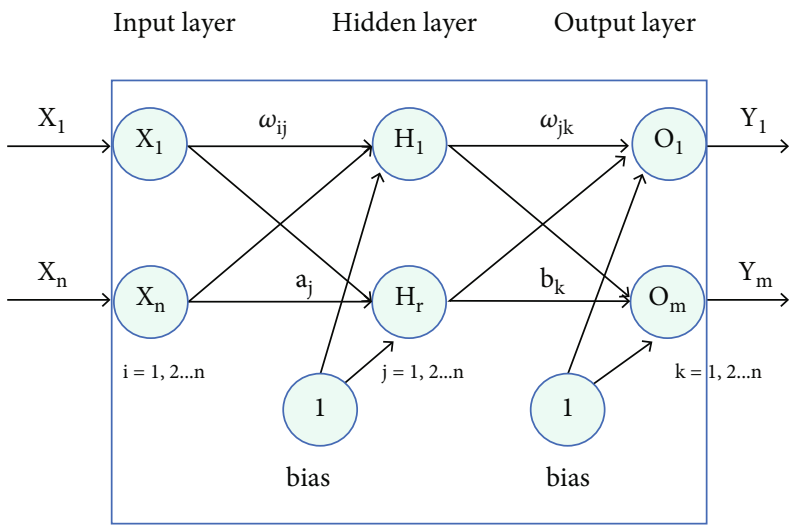

Figure 10: Schematic of BP neural network structure.

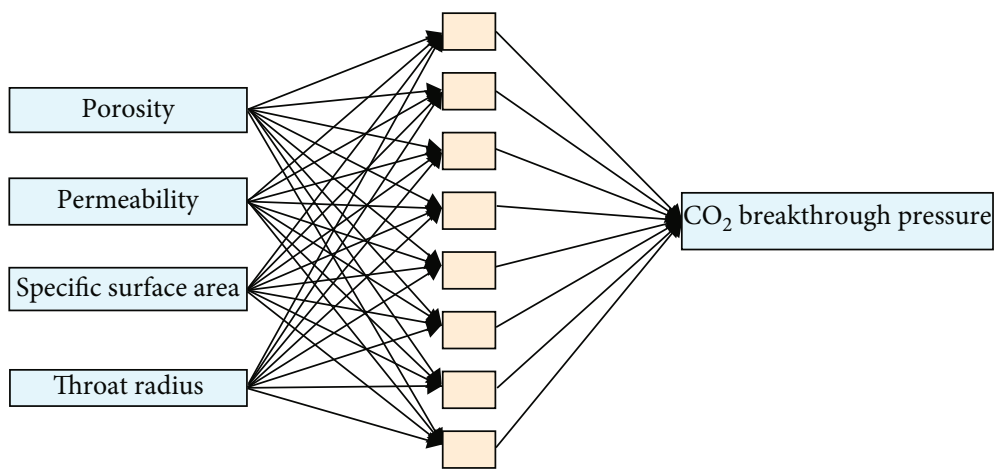

FIgURE 11: Topological structure of the BP neural network.

evaluating the breakthrough pressure of rocks based on only one factor often results in high errors. The neural network model could integrate multiple factors to analyse the breakthrough pressure of rocks, providing a possibility for the prediction of breakthrough pressure. In this section, the neural network model was used to synthesise the factors analysed above, which has a certain correlation with the breakthrough pressure of rocks, to predict this breakthrough pressure.

4.1. Introduction to Neural Network Model. ANN, also known as neural network, is a data processing model. It was inspired by biological neural networks and developed. Its internal calculations are connected by a large number of neurons, and then they are adjusted by external information. The means of adjusting its own structure is mainly by changing the weights between its connecting neurons, making it capable of solving practical problems.

\subsection{Prediction Model Establishment of Back Propagation} (BP) Neural Network. The BP network was proposed by a group of scientists headed by Rumelhart and McCelland in 1986 [40]. It is a multilayer feedforward network trained by the error back propagation algorithm. It is one of the most widely used neural network models at present.

In engineering applications, complex nonlinear problems are often encountered, and accurately modelling them mathematically is difficult. In this paper, the BP neural network was used to solve this problem. The BP neural network is a multilayer feed forward neural network that includes input layers, hidden layers, and output layers. The hidden layer could be divided into one or more layers. Its main characteristics are information forward propagation and error backward propagation. In the process of forwarding information propagation, the information passes through the input layer to the hidden layer and then passes through to the final output layer. If the output layer output does not reach the expected result, the error is back propagated and then the weights and thresholds within the adjustment period of the BP error are maintained until the final output result is within an acceptable range. A diagram of the $\mathrm{BP}$ neural network structure is shown in Figure 10.

In Figure 11, $X_{1}, X_{2}, \ldots, X_{n}$ are input values; $Y_{1}, Y_{2}, \ldots, Y_{m}$ are predicted values; and $\omega_{i j}$ and $\omega_{j k}$ are the weight value. The BP neural network could also be considered as a nonlinear function. The input variable is the independent variable of the nonlinear function, and the output variable is the dependent variable of the nonlinear function. When the number of input variables is $n$ and the number of output variables is $m$, it is a nonlinear function mapping relationship from $n$ independent variables to $m$ dependent variables [41].

Before making a BP neural network prediction, the network needs to be trained to make it predictive. The detailed training process of a neural network model could be referred to $\mathrm{Li}[42]$.

4.3. Establishment of BP Neural Network Prediction Model. Considering the degree of influence of various factors on 
TABLE 2: Measured and predicted breakthrough pressures and other input and output data.

\begin{tabular}{|c|c|c|c|c|c|c|c|c|c|c|}
\hline \multirow[b]{2}{*}{ Group } & \multirow[b]{2}{*}{$\begin{array}{l}\text { Sample } \\
\text { number }\end{array}$} & \multirow[b]{2}{*}{$\begin{array}{l}\text { Sample serial } \\
\text { number }\end{array}$} & \multirow[b]{2}{*}{$\begin{array}{l}\text { Porosity } \\
\text { (\%) }\end{array}$} & \multicolumn{2}{|c|}{ Input } & \multicolumn{3}{|c|}{$\begin{array}{l}\text { Breaking pressure } \\
(\mathrm{MPa})\end{array}$} & \multirow[b]{2}{*}{ MSE } & \multirow[b]{2}{*}{$R^{2}$} \\
\hline & & & & $\begin{array}{l}\text { Permeability } \\
\text { (nD) }\left(10^{-21} \mathrm{~m}^{2}\right)\end{array}$ & $\begin{array}{l}\text { Specific surface } \\
\text { area }\left(\mathrm{m}^{2} / \mathrm{g}\right)\end{array}$ & $\begin{array}{l}\text { Throat } \\
\text { radius } \\
(\mathrm{nm})\end{array}$ & $\begin{array}{l}\text { Measured } \\
\text { value }\end{array}$ & $\begin{array}{l}\text { Predictive } \\
\text { value }\end{array}$ & & \\
\hline \multirow{40}{*}{ Training set } & 1 & $\mathrm{H} 1$ & 2.80 & 6.90 & 7.38 & 7 & 4.504 & 3.781 & \multirow{40}{*}{0.447} & \multirow{40}{*}{0.992} \\
\hline & 2 & $\mathrm{H} 2$ & 2.20 & 1072.00 & 6.29 & 5 & 5.422 & 5.339 & & \\
\hline & 3 & H3 & 6.70 & 8.40 & 26.75 & 8 & 3.765 & 3.810 & & \\
\hline & 4 & $\mathrm{H} 4$ & 3.10 & 4.30 & 10.23 & 5 & 5.925 & 5.987 & & \\
\hline & 5 & H5 & 1.60 & 44.00 & 2.35 & 20 & 12.628 & 11.429 & & \\
\hline & 6 & H6 & 2.80 & 36.30 & 9.52 & 6 & 6.044 & 5.934 & & \\
\hline & 7 & $\mathrm{H} 7$ & 3.00 & 1.90 & 7.30 & 38 & 0.357 & 0.386 & & \\
\hline & 8 & $\mathrm{H} 8$ & 1.70 & 3.30 & 4.02 & 7 & 5.413 & 5.279 & & \\
\hline & 9 & H9 & 1.50 & 4325.00 & 3.65 & 24 & 0.160 & 0.138 & & \\
\hline & 10 & $\mathrm{H} 10$ & 4.40 & 1214.00 & 3.26 & 26 & 0.169 & 0.291 & & \\
\hline & 11 & N5 & 0.90 & 37.00 & 10.54 & 7 & 3.189 & 3.721 & & \\
\hline & 12 & N2 & 0.30 & 75.70 & 4.21 & 6 & 4.256 & 5.739 & & \\
\hline & 13 & N3 & 6.60 & 1370.00 & 2.55 & 70 & 0.548 & 0.128 & & \\
\hline & 14 & N4 & 6.60 & 1350.00 & 3.23 & 57 & 0.510 & 0.808 & & \\
\hline & 15 & N1 & 0.70 & 7.80 & 25.32 & 22 & 14.667 & 14.690 & & \\
\hline & 16 & N6 & 0.70 & 0.62 & 21.58 & 6 & 4.458 & 4.537 & & \\
\hline & 17 & N7 & 0.50 & 50.00 & 9.10 & 6 & 3.652 & 4.176 & & \\
\hline & 18 & N8 & 1.90 & 13.30 & 5.26 & 5 & 4.063 & 5.295 & & \\
\hline & 19 & J1 & 0.15 & 34.00 & 21.10 & 8 & 3.200 & 3.272 & & \\
\hline & 20 & $\mathrm{~J} 2$ & 0.06 & 7.00 & 3.80 & 7 & 4.500 & 4.701 & & \\
\hline & 21 & CS01 & 4.30 & 0.73 & 7.70 & 7 & 4.100 & 4.311 & & \\
\hline & 22 & CS02 & 4.30 & 0.86 & 8.90 & 7 & 4.800 & 5.002 & & \\
\hline & 23 & CS03 & 4.50 & 0.27 & 23.30 & 4 & 4.800 & 4.815 & & \\
\hline & 24 & CS04 & 9.10 & 2.75 & 29.00 & 7 & 4.300 & 4.287 & & \\
\hline & 25 & CS05 & 8.70 & 0.18 & 25.90 & 5 & 5.400 & 5.686 & & \\
\hline & 26 & CS06 & 8.70 & 0.16 & 22.50 & 8 & 3.200 & 3.147 & & \\
\hline & 27 & CS07 & 5.00 & 0.77 & 12.90 & 7 & 3.700 & 3.473 & & \\
\hline & 28 & CS10 & 13.00 & 4.70 & 31.70 & 7 & 3.900 & 3.843 & & \\
\hline & 29 & CS11 & 5.40 & 0.93 & 19.50 & 4 & 5.700 & 5.507 & & \\
\hline & 30 & CS12 & 20.60 & 870.00 & 8.80 & 59 & 0.600 & 0.650 & & \\
\hline & 31 & S1 & 26.10 & 4.30 & 30.56 & 8 & 18.800 & 18.808 & & \\
\hline & 32 & S2 & 26.10 & 9.30 & 30.56 & 20 & 17.500 & 17.502 & & \\
\hline & 33 & S3 & 29.90 & 30.90 & 26.21 & 44 & 5.400 & 5.109 & & \\
\hline & 34 & S4 & 29.90 & 19.70 & 36.21 & 21 & 9.900 & 10.028 & & \\
\hline & 35 & S5 & 10.30 & 9.90 & 26.80 & 13 & 16.200 & 16.270 & & \\
\hline & 36 & S6 & 10.30 & 3.40 & 26.80 & 13 & 14.400 & 14.338 & & \\
\hline & 37 & S7 & 24.40 & 549.60 & 20.10 & 260 & 14.000 & 14.216 & & \\
\hline & 38 & S8 & 23.50 & 23.50 & 23.60 & 24 & 14.200 & 14.264 & & \\
\hline & 39 & S9 & 23.40 & 65.60 & 20.60 & 60 & 18.700 & 17.986 & & \\
\hline & 40 & S10 & 23.40 & 64.30 & 20.60 & 42 & 13.470 & 14.139 & & \\
\hline
\end{tabular}


TABLE 2: Continued.

\begin{tabular}{|c|c|c|c|c|c|c|c|c|c|c|}
\hline \multirow[b]{2}{*}{ Group } & \multirow{2}{*}{$\begin{array}{l}\text { Sample } \\
\text { number }\end{array}$} & \multirow{2}{*}{$\begin{array}{c}\text { Sample serial } \\
\text { number }\end{array}$} & \multirow[b]{2}{*}{$\begin{array}{c}\text { Porosity } \\
(\%)\end{array}$} & \multicolumn{2}{|c|}{ Input } & \multicolumn{3}{|c|}{$\begin{array}{l}\text { Breaking pressure } \\
\qquad(\mathrm{MPa})\end{array}$} & \multirow[b]{2}{*}{ MSE } & \multirow[b]{2}{*}{$R^{2}$} \\
\hline & & & & $\begin{array}{l}\text { Permeability } \\
(\mathrm{nD})\left(10^{-21} \mathrm{~m}^{2}\right)\end{array}$ & $\begin{array}{l}\text { Specific surface } \\
\text { area }\left(\mathrm{m}^{2} / \mathrm{g}\right)\end{array}$ & $\begin{array}{c}\text { Throat } \\
\text { radius } \\
(\mathrm{nm})\end{array}$ & $\begin{array}{l}\text { Measured } \\
\text { value }\end{array}$ & $\begin{array}{c}\text { Predictive } \\
\text { value }\end{array}$ & & \\
\hline \multirow{15}{*}{ Prediction set } & 41 & N9 & 0.8 & 26.6 & 9.73 & 3 & 7.951 & 6.813 & \multirow{15}{*}{0.587} & \multirow{15}{*}{0.9885} \\
\hline & 42 & N10 & 0.6 & 3.5 & 4.34 & 75 & 0.115 & 0.138 & & \\
\hline & 43 & N11 & 0.4 & 1.8 & 4.71 & 43 & 0.402 & 0.429 & & \\
\hline & 44 & N12 & 1.5 & 0.08 & 6.14 & 30 & 0.295 & 0.036 & & \\
\hline & 45 & H11 & 1.5 & 12.1 & 1.59 & 7 & 5.312 & 4.338 & & \\
\hline & 46 & $\mathrm{H} 12$ & 2.6 & 15.1 & 4.87 & 6 & 2.786 & 4.201 & & \\
\hline & 47 & H13 & 1.7 & 10.7 & 2.66 & 10 & 1.373 & 1.393 & & \\
\hline & 48 & H14 & 1.7 & 7.3 & 4.98 & 4 & 3.832 & 2.938 & & \\
\hline & 49 & H15 & 0.7 & 13.5 & 1.47 & 8 & 3.475 & 3.562 & & \\
\hline & 50 & CS20 & 11.6 & 40 & 39 & 7 & 4.8 & 4.676 & & \\
\hline & 51 & CS23 & 24 & 15 & 17.4 & 24 & 0.3 & 0.389 & & \\
\hline & 52 & $\mathrm{Z1}$ & 1.2 & 10.2 & 2.52 & 7 & 1.247 & 1.293 & & \\
\hline & 53 & $\mathrm{Z} 2$ & 24.2 & 5.4 & 34.32 & 18 & 17.2 & 17.514 & & \\
\hline & 54 & $\mathrm{Z3}$ & 2.5 & 45 & 2.44 & 22 & 12.826 & 12.978 & & \\
\hline & 55 & $\mathrm{Z4}$ & 5.1 & 12.1 & 46.8 & 13.9 & 13.9 & 13.725 & & \\
\hline
\end{tabular}

the breakthrough pressure of mudstone and the availability of measured data, the measured porosity, permeability, specific surface area, and TOC were used as inputs for the laboratory to collect data, whilst the breakthrough pressure of mudstone was used as an output. The prediction model of this breakthrough pressure was established on the basis of the BP neural network.

In this paper, all the collected data were compared and screened to form a simulated prediction data set. A total of 55 sets of experimental data were selected for training and verification of the BP neural network model. As shown in Table 2, approximately $70 \%$ of the data was used as the training set and roughly 30\% was used as the test set, of which 40 sets of data were used as the training set and 15 sets of data were used as the test set.

A three-layer BP neural network model was used in this paper, with four nodes in the input layer, the $L$ node in the hidden layer, and one node in the output layer. The number of nodes in the hidden layer was selected as follows:

$$
L=\sqrt{n+m}+a,
$$

where $L, n$, and $m$ are the number of nodes in the hidden layer, input layer, and output layer, respectively, and $a$ is an adjustment constant between 1 and 1 .

After different numbers of hidden layer nodes were used for training, the results showed that the training mean square error is small when the number of hidden nodes is 8. Thus, the number of nodes in the hidden layer was selected in this paper. The schematic of the structure is shown in Figure 10.

The input parameters need to be normalised to reduce the effect of individual factor data. In this paper, the map-

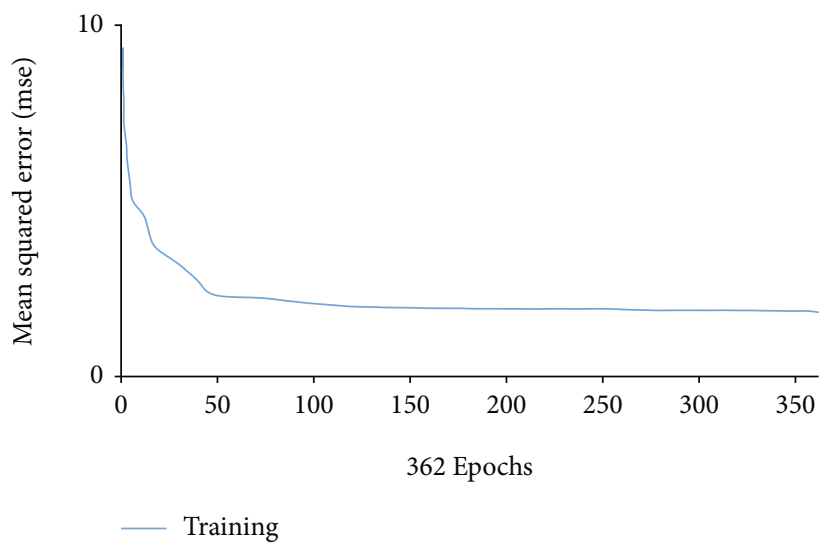

FIGURE 12: Convergence process of BP neural network training.

minmax function was used to normalise the sample data to $[0,1]$. The tansig function was used for the transfer function from the input layer to the hidden layer of the BP neural network, and the purelin function was used for the transfer function from the hidden layer to the output layer. The trainlm function was selected as the function for training the neural network. Finally, the target error was selected as 0.005 , the momentum coefficient was selected as 0.9 , and the maximum training number was selected as 500 times. After programming, simulation was performed in MATLAB.

\subsection{Prediction and Analysis of BP Neural Network Model}

4.4.1. Training Error Curve of BP Neural Network. The BP neural network could make its error continuously decrease through repeated training, and it automatically stops training after reaching a predetermined error value. As shown 


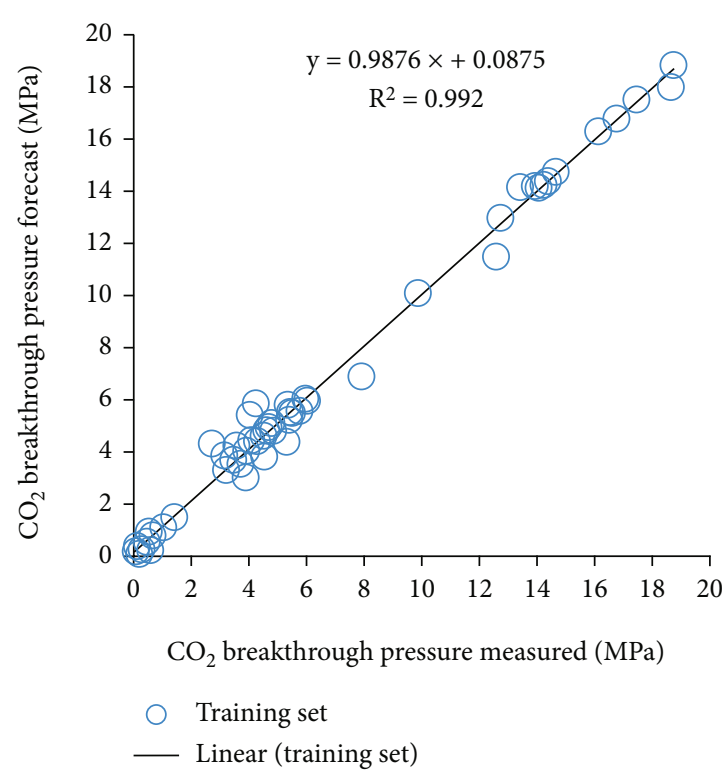

(a) Training set

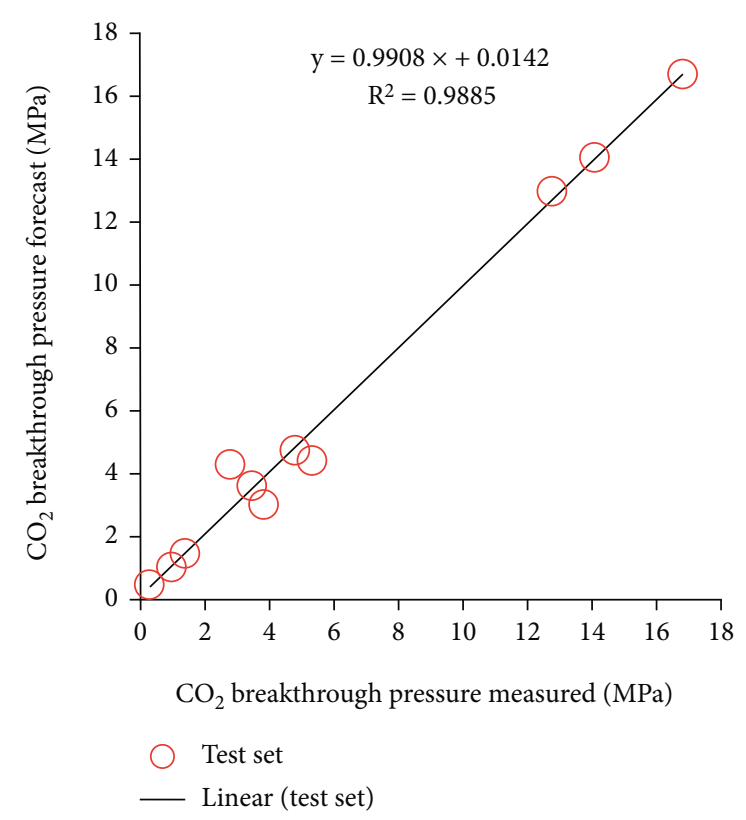

(b) Test set

FIGURE 13: Relationship between measured and predicted values.

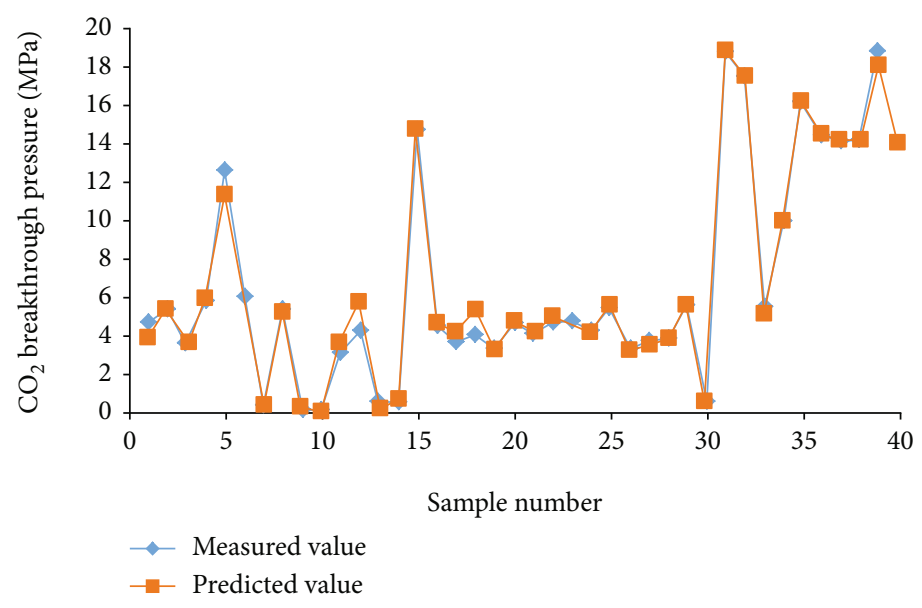

FIGURE 14: Comparison of the prediction results of the training set.

in Figure 12, the target error of 0.005 is satisfied in 362 trainings.

4.4.2. Comparative Analysis of Predicted and Measured Values of BP Neural Network. The predicted value could be obtained by denormalising the prediction result and comparing it with the measured value. The results are shown in Figure 13 and Table 2. The MSE values of the training and test sets were 0.447 and 0.587 , respectively. The $R^{2}$ values were 0.992 and 0.9885 , respectively, which showed that the established BP neural network model has a very good generalization ability. Figure 14 shows the relationship between the measured and predicted values. The ratio of the predicted value to the measured value of the training and test sets of the BP neural network model was approximately 0.9876 and 0.9908 , respectively. The closer the ratio is to 1 , the smaller the error between the measured value and the predicted value and the better the training result of the BP neural network model. Figures 14 and 15 illustrate the comparison of the prediction results of the training and test sets, respectively. The measured and predicted values of the test set are basically the same except for the individual points.

Figures 16 and 17 show the prediction error graphs and prediction relative error graphs of the training and test sets. The relative errors of the training and test sets were within $0.5 \mathrm{MPa}$, except for the individual samples, and the relative errors were within $20 \%$. Large or small errors could be found in the breakthrough pressure measured using laboratory tests. At present, the two methods for testing breakthrough pressure are basically the indirect method and the direct method. The indirect method mainly uses the $\mathrm{Hg}$ pressure 


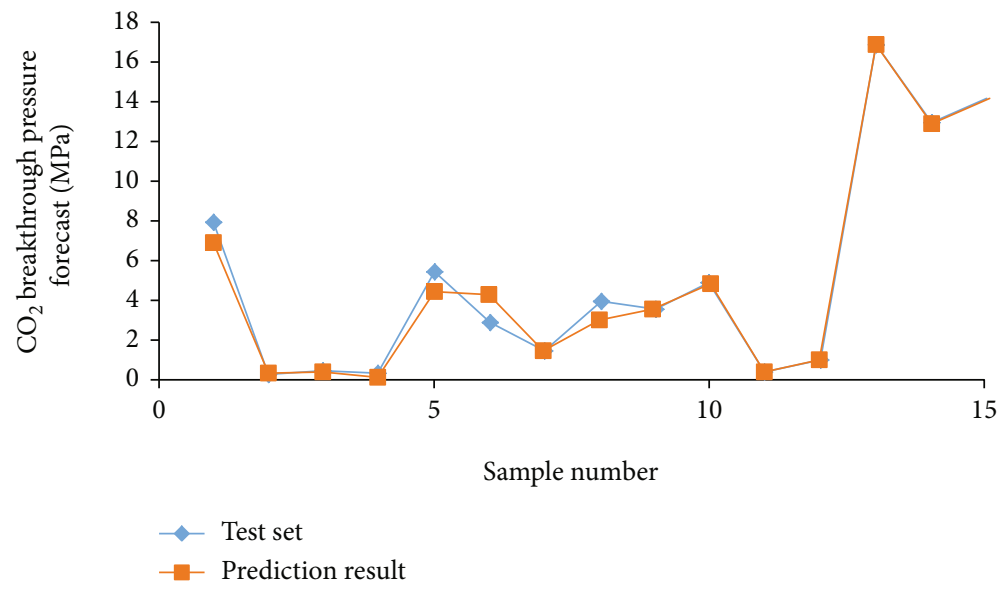

Figure 15: Comparison of the test set and prediction result.

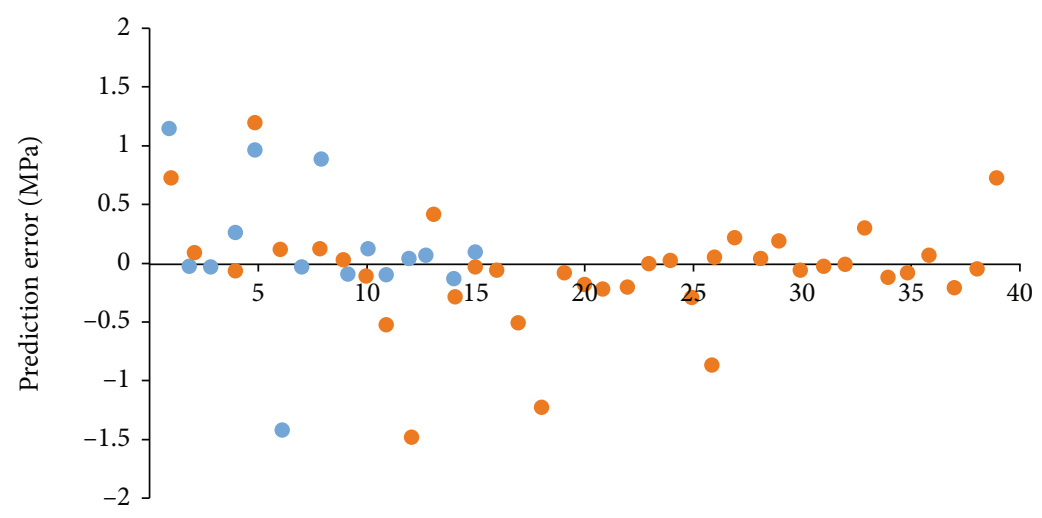

Sample number

FIGURE 16: Prediction error.

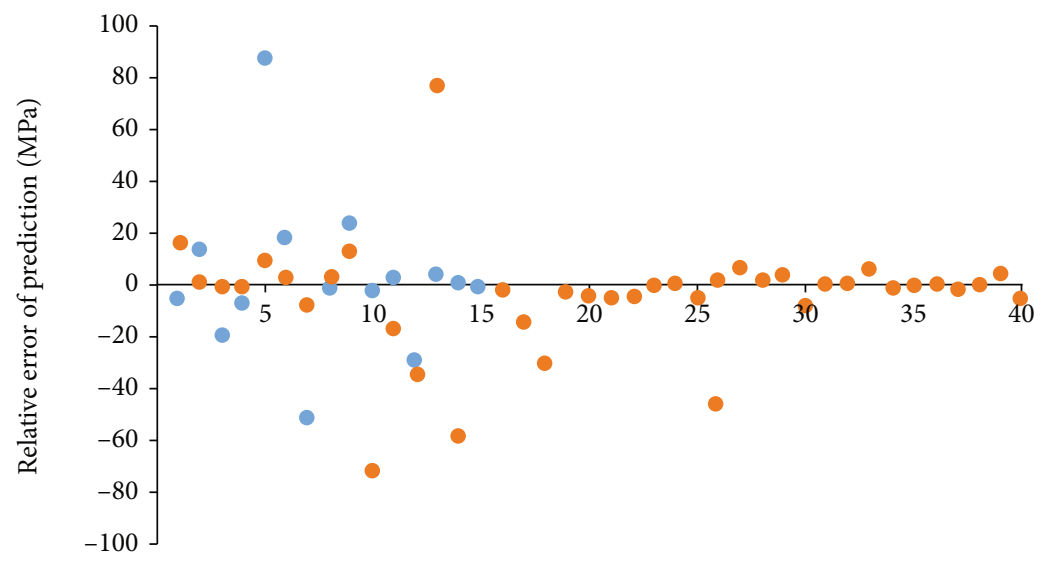

Sample number

FIgURE 17: Prediction relative error.

method, whilst the direct method mainly adopts four methods: the continuous method, the step method, the displacement method, and the pulse method. The Hg intrusion method is simple and fast, but its accuracy is low. In particular, when the anisotropy of the rock sample is significant, the test results are quite different from the true breakthrough pressure. The breakthrough pressure measured by the step method is often higher than the actual breakthrough pressure value of the rock sample. With the continuous method, it is difficult to consider the efficiency of the test and the 
accuracy of the test results. Therefore, the prediction results of the BP neural network model considered that the error is within the range of the measured error. The model could be used as a method to predict the breakthrough pressure of mudstone. The prediction results could also provide a reference for indoor testing and a new idea for determining the breakthrough pressure of mudstone [8].

\section{Analysis and Discussion}

The relationship between rock breakthrough pressure and permeability obtained in this article shows a good correlation, indicating a strong internal relationship between rock permeability and breakthrough pressure. For rock test data from the same source, the relationship between the breakthrough pressure value of rock $\mathrm{CO}_{2}$ and saltwater permeability is more obvious. For general rocks with a wide range of sources, a large error could be found in predicting the breakthrough pressure value by using their permeability. Therefore, to predict the breakthrough pressure of rocks more accurately, analysing it with other rock parameters is necessary.

Porosity, as an important indicator of the development of rock pores, has some inherent relationships with the breakthrough pressure. In general, the higher the rock porosity is, the greater its breakthrough pressure. When the porosity is less than $30 \%$, the data shows that the rock breakthrough pressure value decreases with the increase in porosity. When the porosity is between $35 \%$ and $45 \%$, the breakthrough pressure value of a rock shows an increasing trend with the increase in porosity. The connectivity of the pores, the pore structure, and the morphology of rocks could all have a great effect on its breakthrough pressure.

A strong correlation exists between the breakthrough pressure of a rock and the maximum pore size. With the increase in maximum pore size, the breakthrough pressure decreases sharply. The overall $R^{2}$ is 0.569 , showing a strong correlation. However, the differences in pore morphology, rock composition, temperature, pressure conditions, and other factors that affect the surface tension and contact angle between the gas and liquid fluids to varying degrees cause certain errors in the estimation of breakthrough pressure.

The specific surface area of a rock has multiple effects on its breakthrough pressure. As the specific surface area of a rock increases, its breakthrough pressure tends to increase. The larger the specific surface area of the rock is, the finer the particles and the lower the pore radius, resulting in an increase in breakthrough pressure. The higher the degree of cementation between rocks, the smaller the specific surface area. A better degree of cementation could reduce the permeability of rock pores, which could lead to an increase in breakthrough pressure.

The natural density of rocks could reflect their compactness to a certain extent. In general, the higher the density of the rock is, the better its cementation and the higher its breakthrough pressure. With the increase in depth, the breakthrough pressure of a rock shows an upward trend. The reason is that for the same type of rock, the deeper the depth is, the denser the rock and the better the degree of cementation, leading to a decrease in permeability and an increase in breakthrough pressure. However, from the overall data, no correlation exists between the breakthrough pressure of a rock and its density and depth.

The development of microfractures in rocks is affected by TOC content; however, this is not the main factor. This development is determined by the state of stress experienced during the development process. According to the data collected in this article, TOC content does not fundamentally reflect the magnitude of the breakthrough pressure of a rock.

The analysis showed that the breakthrough pressure of a rock is most closely related to its permeability and the maximum throat radius, followed by the relationship between porosity and specific surface area, and the weakest relationship is between the density and sampling depth, whilst TOC content has no correlation. In this paper, many different combinations of input variables were explored. Finally, porosity, permeability, specific surface area, and maximum throat radius were taken as the input variables, and the breakthrough pressure of mudstone was used as the output to minimise the prediction error. Approximately $70 \%$ and $30 \%$ of the data were randomly selected as the training set and test set, respectively, to train the network to have prediction ability, including 40 groups of data as the training set and 15 groups of data as the test set. The MSE values of the training and test sets were 0.447 and 0.587 , respectively, and the $R^{2}$ values were 0.992 and 0.9885 , respectively. These findings are consistent with the BP ANN study of the influencing factors of enhanced geothermal system production performance [43] and another study of surface roughness and energy consumption of machined parts [44]. The relative errors of the training and test sets were within $0.5 \mathrm{MPa}$, and the relative errors were within $20 \%$ except for the individual samples, showing that this method is more accurate and effective than other linear prediction methods [12]. Although the flow of $\mathrm{CO}_{2}$ in rocks is a matter of multiphase saturatedunsaturated coupling problem [45-47], the prediction results of the BP neural network model was within the range of the measured error and this model could be used as a method to predict the breakthrough pressure of mudstone.

\section{Conclusion}

On the basis of the study of the relationship between the breakthrough pressure of $\mathrm{CO}_{2}$ and other parameters (permeability, porosity, maximum throat radius, specific surface area, density, depth, and TOC content), the following conclusions are drawn:

(1) The breakthrough pressure of mudstone is influenced by many factors, but the degree of effect varies. The analysis showed that the breakthrough pressure of a rock is closely related to its permeability and maximum throat radius, followed by its porosity and specific surface area. The correlation with rock density, sampling depth, and TOC content is the weakest

(2) The breakthrough pressure of a rock is greatly influenced by its geological background. According to the 
analysis, for rock samples from the same site, the breakthrough pressure and other conventional parameters (permeability, porosity, maximum throat radius, specific surface area, density, depth, and TOC content) show a strong regularity, and the relationship between the rocks and other parameters is quite different

(3) The relationship between the breakthrough pressure of a rock and other parameters is strong or weak. However, regardless of what single index is used to predict the breakthrough pressure, a good prediction effect could not be obtained. The breakthrough pressure of a rock could be predicted accurately by means of a neural network, which provides a new means to determine the parameters of its breakthrough pressure

\section{Data Availability}

The data supporting the results of this study and are reported in Tables 1 and 2 .

\section{Conflicts of Interest}

The authors declare that there is no conflict of interest regarding the publication of this paper.

\section{Acknowledgments}

The authors acknowledge the support from the Natural Science Foundation of China (42002258) and the Research Foundation of East China University of Technology (DHBK2019234).

\section{References}

[1] L. LianBo, S. Wang, D. Guo, N. Hongwei, and G. Shiwang, "CO $\mathrm{CO}_{2}$. Energy balance analysis of trap test device," Proceedings of the CSEE, vol. 37, no. 11, pp. 3201-3206, 2017.

[2] T. Wang, L. Fei, F. Mengxiang, X. Zhixiang, and L. Zhenzhen, "Research progress of carbon dioxide capture technology with two-phase absorbent," Proceedings of the CSEE, vol. 41, no. 4, pp. 1186-1196, 2021.

[3] M. Jianfeng and X. Ma, "Analysis of CCUs technology development trend in China," Proceedings of the CSEE, vol. 39, no. 9, pp. 2537-2544, 2019.

[4] J. Dalin, Y. Lin, W. Ning, L. Shengnan, N. Ligong, and L. Xiaochun, "Suitability evaluation of coal-fired power plant retrofitting with CCUs: a case study of former Shenhua Group power plant," Proceedings of the CSEE, vol. 39, no. 19, pp. 5835-5842, 2019.

[5] S. Bachu, D. Bonijoly, J. Bradshaw, R. Burruss, S. Holloway, and N. P. Christensen, " $\mathrm{CO}_{2}$ storage capacity estimation: methodology and gaps," International Journal of Greenhouse Gas Control, vol. 1, no. 4, pp. 430-443, 2007.

[6] S. Bachu, "Sequestration of $\mathrm{CO}_{2}$ in geological media: criteria and approach for site selection in response to climate change," Energy Conversion and Management, vol. 41, no. 9, pp. 953970, 2000.
[7] L. Xiaoguang, $\mathrm{CO}_{2}$ Study on Mechanical Effects of Caprock for $\mathrm{CO}_{2}$ Geological Sequestration, Jilin University, 2013.

[8] S. Gao, W. Ning, and L. Xiaochun, "Review of $\mathrm{CO}_{2}$ breakthrough pressure measurement methods on caprocks," Rock and Soil Mechanics, vol. 36, no. 9, pp. 2716-2727, 2015.

[9] L. K. Thomas, D. L. Katz, and M. R. Tek, "Threshold pressure phenomena in porous media," Society of Petroleum Engineers Journal, vol. 8, no. 2, 1968.

[10] M. R. Tek and D. L. Katz, Threshold pressure in gas storage, American Gas Association, Arlington, Virginia, 1970.

[11] T. T. Schowalter, "Mechanics of secondary hydrocarbon migration and entrapment," AAPG Bulletin, vol. 63, pp. 723760, 1979.

[12] A. Busch and A. Amann-Hildenbrand, "Predicting capillarity of mudrocks," Marine and Petroleum Geology, vol. 45, no. 4, pp. 208-223, 2013.

[13] H. Haiping and D. Hongwen, "Gas lubricated seals for centrifugal pumps," Natural gas Geosciences, vol. 1995, no. 20, pp. 23, 1995.

[14] Y. Yang and A. C. Aplin, "Influence of lithology and compaction on the pore size distribution and modelled permeability of some mudstones from the Norwegian margin," Marine and Petroleum Geology, vol. 15, no. 2, pp. 163-175, 1998.

[15] S. R. Moosavi, D. A. Wood, M. A. Ahmadi, and A. Choubineh, "ANN-based prediction of laboratory-scale performance of $\mathrm{CO}_{2}$-foam flooding for improving oil recovery," Natural Resources Research, vol. 28, no. 4, pp. 16191637, 2019.

[16] M.-A. Ahmadi, M. R. Ahmadi, S. M. Hosseini, and M. Ebadi, "Connectionist model predicts the porosity and permeability of petroleum reservoirs by means of petro-physical logs: application of artificial intelligence," Journal of Petroleum Science and Engineering, vol. 123, pp. 183-200, 2014.

[17] M. A. Ahmadi and S. Ding, "Developing a robust surrogate model of chemical flooding based on the artificial neural network for enhanced oil recovery implications," Mathematical Problems in Engineering, vol. 2015, 9 pages, 2015.

[18] D. Ito, K. Akaku, T. Okabe, T. Takahashi, and T. Tsuji, "Measurement of threshold capillary pressure for seal rocks using the step-by-step approach and the residual pressure approach," Energy Procedia, vol. 4, pp. 5211-5218, 2011.

[19] A. Hildenbrand, S. Schlömer, and B. M. Krooss, "Gas breakthrough experiments on fine-grained sedimentary rocks," Geofluids, vol. 2, no. 1, 23 pages, 2002.

[20] A. Hildenbrand, S. Schlömer, B. M. Krooss, and R. Littke, "Gas breakthrough experiments on pelitic rocks: comparative study with $\mathrm{N}_{2}, \mathrm{CO}_{2}$ and $\mathrm{CH}_{4}$," Geofluids, vol. 4, no. 1, 80 pages, 2004.

[21] Y. Yang and A. C. Aplin, Permeability and Petrophysical Properties of 30 Natural Mudstones, vol. 112, no. B3, 2007John Wiley \& Sons, Ltd, 2007.

[22] T. M. Al-Bazali, J. Zhang, M. E. Chenevert, and M. M. Sharma, Measurement of the Sealing Capacity of Shale Caprocks, 2005.

[23] T. M. Al-Bazali, J. Zhang, M. E. Chenevert, and M. M. Sharma, "An experimental investigation on the impact of capillary pressure, diffusion osmosis, and chemical osmosis on the stability and reservoir hydrocarbon capacity of shales," in Offshore Europe, Society of Petroleum Engineers, Aberdeen, UK, 2009.

[24] P. Marschall, S. Horseman, and T. Gimmi, "Characterisation of gas transport properties of the Opalinus clay, a potential host rock formation for radioactive waste disposal," Oil \& 
Gas Science and Technology e Revue d'IFP, vol. 60, no. 1, pp. 121-139, 2005.

[25] A. Amann-Hildenbrand, P. Bertier, A. Busch, and B. M. Krooss, "Experimental investigation of the sealing capacity of generic clay-rich caprocks," International Journal of Greenhouse Gas Control, vol. 19, pp. 620-641, 2013.

[26] P. F. Boulin, P. Bretonnier, V. Vassil, A. Samouillet, M. Fleury, and J. M. Lombard, Entry Pressure Measurements Using Three Unconventional Experimental Methods, Society of Core Analysts, Austin, Texas, USA, 2011.

[27] C. Zhang and Q. Yu, "The effect of water saturation on methane breakthrough pressure: an experimental study on the carboniferous shales from the eastern Qaidam Basin, China," Journal of Hydrology, vol. 543, pp. 832-848, 2016.

[28] D. N. Espinoza and J. C. Santamarina, " $\mathrm{CO}_{2}$ breakthrough-caprock sealing efficiency and integrity for carbon geological storage," International Journal of Greenhouse Gas Control, vol. 66, pp. 218-229, 2017.

[29] M. Ono, H. Kameya, K. Hosoda, Y. Kamidozono, and H. Azuma, "Experimental measurements of threshold pressure for modeling saline aquifers in Japan," Energy Procedia, vol. 37, pp. 5456-5463, 2013.

[30] S. Schlömer and B. M. Krooss, "Experimental characterisation of the hydrocarbon sealing efficiency of cap rocks," Marine and Petroleum Geology, vol. 14, no. 5, pp. 565-580, 1997.

[31] N. Tonnet, G. Mouronval, P. Chiquet, and D. Broseta, "Petrophysical assessment of a carbonate-rich caprock for $\mathrm{CO}_{2}$ geological storage purposes," Energy Procedia, vol. 4, pp. 5422$5429,2011$.

[32] J. E. Heath, T. A. Dewers, B. J. O. L. McPherson, M. B. Nemer, and P. G. Kotula, "Pore-lining phases and capillary breakthrough pressure of mudstone caprocks: sealing efficiency of geologic $\mathrm{CO}_{2}$ storage sites," International Journal of Greenhouse Gas Control, vol. 11, pp. 204-220, 2012.

[33] A. Busch, A. Amann, P. Bertier, M. Waschbusch, and B. M. Krooss, "The significance of caprock sealing integrity for $\mathrm{CO}_{2}$ storage," in SPE International Conference on CO2 Capture, Storage, and Utilization, 2010.

[34] L. Xiongyan, Q. Ruibao, P. Haitao, C. Jingji, and W. Peng, "Establishment and application of a high-precision permeability model," Journal of China University of Petroleum, vol. 44, no. 6, pp. 14-20, 2020.

[35] P. Haochen, X. Jian, D. Huaishuo, R. Chenggan, and L. Wenhai, "Experimental study on the physical properties of rocks with different lithology," Petrochemical Industry Application, vol. 39, no. 5, pp. 97-102, 2020.

[36] E. S. Sprunt, "Stand tall and speak up: we can be a key player in the solution to global warming," Journal of Petroleum Technology: Stand Tall and Speak UP, vol. 58, no. 5, pp. 10-12, 2006.

[37] D. M. Jarvie, R. J. Hill, T. E. Ruble, and R. M. Pollastro, "Unconventional shale-gas systems: the Mississippian Barnett Shale of north-central Texas as one model for thermogenic shale-gas assessment," AAPG Bulletin, vol. 91, no. 4, pp. 475-499, 2007.

[38] F. Wang and J. Gale, "Screening criteria for shale-gas systems," Gulf Coast Association of Geological Societies, vol. 59, pp. 779793, 2009.

[39] Z. Cheng, Breakthrough Pressure and Seepage Characteristics of Carboniferous Unsaturated Shale in Eastern Qaidam Basin, China University of Geosciences, Beijing, 2018.
[40] G. Zhang, X. Wang, and Z. Du, "Research on the prediction of solar energy generation based on measured environmental data," International Journal of $u$-and e-Service, Science and Technology, vol. 8, no. 5, pp. 385-402, 2015.

[41] X. U. Hongdong, Research on Cost Forecast of Transmission and Transformation Project Based on Artificial Neural Network, North China Electric Power University, 2017.

[42] L. Hongkun, Research on Marine Diesel Engine Fault Diagnosis Method Based on Information Fusion Technology and Application, Dalian University of Technology, Dalian, 2003.

[43] L. Zhou, Y. Zhang, Z. Hu et al., "Analysis of influencing factors of the production performance of an enhanced geothermal system (EGS) with numerical simulation and artificial neural network (ANN)," Energy \& Buildings, vol. 200, pp. 31-46, 2019.

[44] X. Xiaoping, L. Jingjing, Z. Chao, Z. Guanghui, and X. Yang, "Prediction method of surface roughness and energy consumption of machined parts based on ANN," Applied science and technology, 2021.

[45] X. Zhang, E. Zhai, Y. Wu, D. Sun, and Y. Lu, "Theoretical and numerical analyses on hydro-thermal-salt-mechanical interaction of unsaturated salinized soil subjected to typical unidirectional freezing process," International Journal of Geomechanics, vol. 21, no. 7, article 04021104, 2021.

[46] Y. Wu, E. Zhai, X. Zhang, G. Wang, and Y. Lu, "A study on frost heave and thaw settlement of soil subjected to cyclic freeze-thaw conditions based on hydro-thermal-mechanical coupling analysis," Cold Regions Science and Technology, vol. 188, article 103296, 2021.

[47] Y. Wu, X. Wang, X. Zhang et al., "Experimental study on the treatment of sludge discharged from an in situ soil washing plant by vacuum preloading," Environmental Engineering Science, vol. 38, no. 9, pp. 899-909, 2021. 